\title{
Utilização de rejeito de caulim da Amazônia na síntese da zeólita A
}

\section{(The use of kaolin wastes from the Amazon region on the synthesis of zeolite A)}

\author{
A. A. B. Maia ${ }^{1}$, E. Saldanha ${ }^{1}$ R. S. Angélica ${ }^{2}$, C. A. G. Souza ${ }^{1}$, R. F. Neves ${ }^{1}$ \\ ${ }^{1}$ Programa de Pós-Graduação em Engenharia Química, Universidade Federal do Pará \\ ${ }^{2}$ Centro de Geociências, Universidade Federal do Pará \\ anabmaia@yahoo.com.br
}

\begin{abstract}
Resumo
Zeólita A e hidroxisodalita foram sintetizadas a partir de um rejeito industrial do processo de beneficiamento de caulim para papel, de indústrias da região amazônica. Esse rejeito é composto essencialmente por caulinita e possui razão $\mathrm{SiO}_{2} / \mathrm{Al}_{2} \mathrm{O}_{3}$ igual à requerida para esses dois tipos de zeólitas. Dessa maneira, o processo de síntese passou por duas etapas: primeiramente o caulim foi submetido ao tratamento térmico, através de calcinação a $700{ }^{\circ} \mathrm{C}$ por $2 \mathrm{~h}$, para transformação de caulinita em metacaulinita. A metacaulinita obtida reagiu com $\mathrm{NaOH}$ em solução, em condições hidrotermais, através de autoclavagem estática, nas temperaturas de 80,110 e $150{ }^{\circ} \mathrm{C}$ por $24 \mathrm{~h}$. Os materiais de partida foram identificados e caracterizados por difração de raios X (DRX) e microscopia eletrônica de varredura (MEV) e os produtos sintetizados, por meio de $\mathrm{DRX}, \mathrm{MEV}$, análises térmica diferencial e termogravimétrica, e espectroscopia de infravermelho. No processo realizado a $150{ }^{\circ} \mathrm{C}$ foi obtida uma mistura de zeólita A e hidroxisodalita. A $110{ }^{\circ} \mathrm{C}$ houve a formação de zeólita A. Contudo, na menor temperatura de síntese $\left(80^{\circ} \mathrm{C}\right)$ não houve formação de material cristalino para as condições do processo estabelecidas.
\end{abstract}

Palavras-chave: caulinita, rejeito de caulim, síntese, zeólita A, hidroxisodalita.

Abstract

Zeolite A and Hydroxysodalite were synthesized after kaolin wastes from kaolin processing industries for paper coating, located in the Amazon region. The waste is mainly composed by kaolinite, which has the same $\mathrm{SiO}_{2} / \mathrm{Al}_{2} \mathrm{O}_{3}$ ratio requested for those two zeolites. Thereby, synthesis process may occur in two steps: 1) the kaolin was submitted to thermal treatment, through calcination process at $700{ }^{\circ} \mathrm{C}$ for $2 \mathrm{~h}$, in order to obtain the metakaolinite phase. The metakaolinite obtained reacted with NaOH solution, in hydrothermal conditions, using autoclaves, at the following temperatures: 80,110 and $150^{\circ} \mathrm{C}$ for $24 \mathrm{~h}$. The starting materials were identified and characterized by means of X-Ray Diffraction (XRD) and Scanning Electron Microscopy (SEM) analysis and synthesis products were characterized by means of XRD, SEM. Thermal Methods (DTA-DTG) and Fourier Transformed Infrared Spectroscopy (FTIR). A mixture of Zeolite A and Hydroxysodalite was obtained through this process at $150^{\circ} \mathrm{C}$. In the temperature of $110^{\circ} \mathrm{C}$ there was only the Zeolite A formation. Nevertheless, in the lowest synthesis temperature $\left(80^{\circ} \mathrm{C}\right)$ there was no crystalline material formation for the established conditions.

Keywords: kaolinite, kaolin wastes, synthesis, zeolite A, hydroxysodalite.

\section{INTRODUÇÃO}

Embora a atividade mineradora tenha uma grande importância na economia do estado do Pará, as inúmeras empresas instaladas na região, devido sua elevada produção, geram uma quantidade significativa de rejeito, que é disposto, de diversas formas, ao meio ambiente. No estado do Pará existem três indústrias de beneficiamento de caulim para papel: Caulim da Amazônia S.A. (CADAM), Pará Pigmentos S. A. (PPSA) e Imerys Rio Capim Caulim S. A. (IRCC). Em 2005, segundo dados declarados por essas empresas ao DNPM, a produção de caulim beneficiado cresceu 1,3\% em relação ao ano anterior, passando de 2,38 milhões de toneladas para 2,41 milhões [1].

No caso do beneficiamento de caulim, dois tipos de rejeitos são gerados: o primeiro é basicamente constituído de quartzo, proveniente da etapa de desareiamento (cerca de $10 \%$ ); já no segundo tipo a quantidade resultante é mais significante, em torno de $26 \%$ da produção bruta, devido ser originado das etapas de centrifugação, separação magnética, branqueamento e filtragem, sendo esse tipo armazenado em grandes lagoas de sedimentação. Esse resíduo é o próprio caulim, constituído basicamente por caulinita, sendo que a sua granulometria é inadequada para a produção de papel, caracterizando dessa maneira em um material com grande potencial para ser empregado como matéria prima em vários processos e para diferentes tipos de aplicações. Por esse motivo, o grupo de Mineralogia e Geoquímica Aplicada, da Universidade Federal do Pará vem utilizando esse material para o desenvolvimento de trabalhos, como por exemplo, síntese de zeólitas [2], produção de refratários [3], pozolanas para a indústria de cimento [4], e agregados na construção civil [5], dentre outros.

As zeólitas englobam um grande número de minerais 
naturais e sintéticos que apresentam características comuns. São aluminosilicatos hidratados de metais alcalinos ou alcalinos terrosos (principalmente sódio, potássio, magnésio e cálcio), estruturados em redes cristalinas tri-dimensionais, compostos de tetraedros do tipo $\mathrm{TO}_{4}(\mathrm{~T}=\mathrm{Si}, \mathrm{Al}, \mathrm{B}, \mathrm{Ge}, \mathrm{Fe}$, $\mathrm{P}, \mathrm{Co}$ ) unidos nos vértices por meio de átomos de oxigênio [6]. Devido suas propriedades originadas da estrutura microporosa, as zeólitas são amplamente usadas do processo de adsorção, troca iônica e catálise.

A zeólita $\mathrm{A}$ com íon $\mathrm{Na}^{+}$como cátion trocável (zeólita $\mathrm{NaA}$ ), que possui fórmula geral $\mathrm{Na}_{12} \mathrm{Al}_{12} \mathrm{Si}_{12} \mathrm{O}_{48} 27 \mathrm{H}_{2} \mathrm{O}$, tem uma razão $\mathrm{Si} / \mathrm{Al}$ mínima em relação a outras zeólitas e alta capacidade de troca catiônica. É facilmente sintetizada com uma morfologia cúbica bem característica e poucos micrometros de tamanho [7].

A estrutura cúbica da zeólita A ( $\mathrm{a}=24,6 \AA$, grupo espacial $\mathrm{Fm}-3 \mathrm{c}$ ) possui arranjos tridimensionais compostos por unidades tetraédricas de $\mathrm{SiO}_{4}$ e $\mathrm{AlO}_{4}$ na proporção 1:1 e é geralmente descrita em termos da unidade sodalita (ou $\beta$-cadeia), e anel duplo de 4 tetraedros. A interconexão dessas unidades produz a larga cavidade, 11,4 $\AA \mathrm{em}$ diâmetro ( $\alpha$ - cadeia), e dois sistemas de canais cruzados. A neutralidade elétrica é ativada pela inclusão do íon $\mathrm{Na}^{+}$ na cadeia, além disso, um número de moléculas de água se difunde facilmente. Do ponto de vista termodinâmico, a zeólita A é uma fase metaestável e tende a transformar em hidroxisodalita $\left(\mathrm{Na}_{6} \mathrm{Al}_{6} \mathrm{Si}_{6} \mathrm{O}_{24 .} 8 \mathrm{H}_{2} \mathrm{O}\right)$ com o tempo [8].

A zeólita A é especialmente atrativa em suas aplicações devido possuir poros de tamanho efetivo que podem ser facilmente variados pela troca de íon. Ela pode comportar-se como um cristal de poros de dimensões variáveis, dependendo

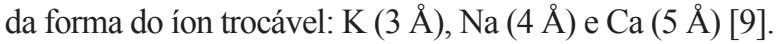

Quando a metacaulinita - obtida a partir da calcinação da caulinita acima de $550^{\circ} \mathrm{C}$ - reage com $\mathrm{NaOH}$ a uma temperatura de 70 a $105^{\circ} \mathrm{C}$; zeólita A é geralmente o produto obtido [10-12]. A síntese da zeólita A, assim como de todas aquelas zeólitas de baixa sílica, consiste essencialmente de duas etapas: (i) ativação térmica da caulinita para obtenção da metacaulinita; (ii) reação hidrotérmica da metacaulinita com um meio alcalino aquoso.

A zeólita A é utilizada frequentemente nas indústrias de petróleo e química como catalisador, trocadora de íon e peneira molecular [13], como um eficiente agente de amolecimento de água na formulação de detergente [14] e na remoção de água na secagem de gás refrigerante [15].

A hidroxisodalita é cristalizada em condições hidrotermais, quando se adiciona ao caulim uma solução de hidróxido de sódio. Também pode ser formada a partir de metacaulinita, utilizando essa mesma base por longo período de tempo. Neste caso, primeiramente é formada zeólita A e logo após a hidroxisodalita [16].

Com o objetivo de sintetizar zeólita A, foi utilizado como material de partida o resíduo caulinítico mencionado anteriormente, mais especificamente o proveniente da centrifugação. Com isto, propõe-se uma forma de aproveitamento do mesmo, a fim de trazer além de benefícios de caráter ambiental, no sentido de diminuição desse rejeito, possibilitar a transformação de um material de baixo valor comercial em outro de alto valor agregado (zeólitas).

\section{MATERIAIS E MÉTODOS}

\section{Materiais de partida}

Como fonte de silício e alumínio foi usado o rejeito de beneficiamento de caulim oriundo de uma indústria de mineração do município de Ipixuna, no estado do Pará. A fonte de metal alcalino usado na síntese foi o hidróxido de sódio (Casa da Química Ind. Com. Ltda.).

A mistura reacional utilizada na síntese apresentou a seguinte composição molar: $1,26 \mathrm{Na}_{2} \mathrm{O} \cdot \mathrm{Al}_{2} \mathrm{O}_{3} \cdot 2 \mathrm{SiO}_{2} \mathrm{nH}_{2} \mathrm{O}$ [17].

\section{Processo de sintese}

O processo de síntese ocorreu através de duas etapas. Na primeira, o caulim foi calcinado em mufla $700^{\circ} \mathrm{C}$ por $2 \mathrm{~h}$, para que toda caulinita se transforme em metacaulinita. A segunda ocorreu em uma autoclave, em condições hidrotérmicas, na qual à quantidade calculada de metacaulinita foi adicionada a uma solução aquosa de hidróxido de sódio $5 \mathrm{~N}$, seguida de autoclavagem estática em estufa a 80,110 e $150{ }^{\circ} \mathrm{C}$ por $24 \mathrm{~h}$. Posteriormente, cada produto formado foi lavado e filtrado com água destilada até o $\mathrm{pH} 7$, e em seguida seco em estufa a $100^{\circ} \mathrm{C}$ por $6 \mathrm{~h}$.

\section{Caracterização dos materiais}

A caracterização do material precursor e dos produtos sintetizados nas diferentes temperaturas do processo foi feita por meio das técnicas instrumentais descritas a seguir:

- Analise Térmica ATD/ATG em equipamento modelo PL Thermal Sciences. Foi usado cadinho de alumina com cerca de $10 \mathrm{mg}$ de amostra, com varredura na faixa de temperatura ambiente até $1000{ }^{\circ} \mathrm{C}$, e velocidade de aquecimento de $20^{\circ} \mathrm{C} / \mathrm{min}$ sob atmosfera estática.

- As análises de difração de raios X (DRX) foram feitas em difratômetro modelo X'Pert Pro MPD (PW 3040/60) PANalytical, com goniômetro PW3050/60 (teta/teta) e com tubo de raios $\mathrm{X}$ cerâmico de anodo de $\mathrm{Cu}\left(\mathrm{K}_{\alpha 1}=1,540598\right.$ Å) modelo PW3373/00, foco fino longo, filtro $\mathrm{K}_{\beta}$ de Ni, detector X'Celerator RTMS (Real Time Multiple Scanning) no modo scanning e com active length $2,122^{\circ}$. Foram as seguintes as condições instrumentais: varredura $5^{\circ}$ a $75^{\circ} \mathrm{em}$ $2 \theta, 40 \mathrm{kV}, 40 \mathrm{~mA}$, passo $0,02^{\circ} \mathrm{em} 2 \theta$ e tempo/passo $5 \mathrm{~s}$, fenda divergente $1 / 2^{\circ}$ e anti-espalhamento $1^{\circ}$, máscara $10 \mathrm{~mm}$, movimento da amostra spinning, com 1 rps. A aquisição de dados foi feita com o software X'Pert Data Collector, versão 2.1a, e o tratamento dos dados com o software $X^{\prime}$ Pert HighScore versão 2.1b.

- Microscopia Eletrônica de Varredura (MEV) com microscópio Zeiss modelo LEO 1430. A metalização, uma película de ouro de espessura media $15 \mathrm{~nm}$ sobre as amostras, foi feita com equipamento Emitech K550. As imagens foram geradas por elétrons secundários com voltagens de $20 \mathrm{kV}$, e 
registrados em alta resolução.

- Espectroscopia de Infravermelho (EIV) com um espectrofotômetro Perkin Elmer FTIR 1760X, com transformada Fourier, na região $4000-400 \mathrm{~cm}^{-1}$ com uma resolução de $4 \mathrm{~cm}^{-1}$, sendo as pastilhas produzidas com $\mathrm{KBr}$.

Os produtos foram nomeados da seguinte maneira: M-8024, M-110-24 e M-150-24 correspondentes às temperaturas de reação de 80,110 e $150^{\circ} \mathrm{C}$, respectivamente, para o tempo de $24 \mathrm{~h}$.

\section{RESULTADOS E DISCUSSÃO}

Os difratogramas de raios $\mathrm{X}$ do rejeito de caulim e do mesmo calcinado a $700{ }^{\circ} \mathrm{C}$ por $2 \mathrm{~h}$ são apresentados na Fig. 1. Verificouse que o caulim é constituído essencialmente pelo mineral caulinita com a presença dos seus dois picos principais em $7,15 \AA$ (001) e 3,56 $\AA$ (002). Esse material também apresentou picos de anatásio e quartzo, de menores intensidades, quando comparados aos picos principais da caulinita. Vale ressaltar que estes minerais, de um modo geral, estão sempre presentes nas ocorrências de caulim da região, são separados durante o processamento, porém depois são novamente lançados nas bacias de rejeito. Através do tratamento térmico verificou-se a transformação da caulinita em metacaulinita, ocasionada pelo completo rompimento da estrutura cristalina. Os picos de quartzo e anatásio ainda são detectados nesse material.

As imagens de microscopia eletrônica de varredura do material de partida (rejeito de caulim) e do material intermediário (metacaulinita) estão apresentadas na Fig. 2. Observou-se que o material de partida, sem tratamento térmico,

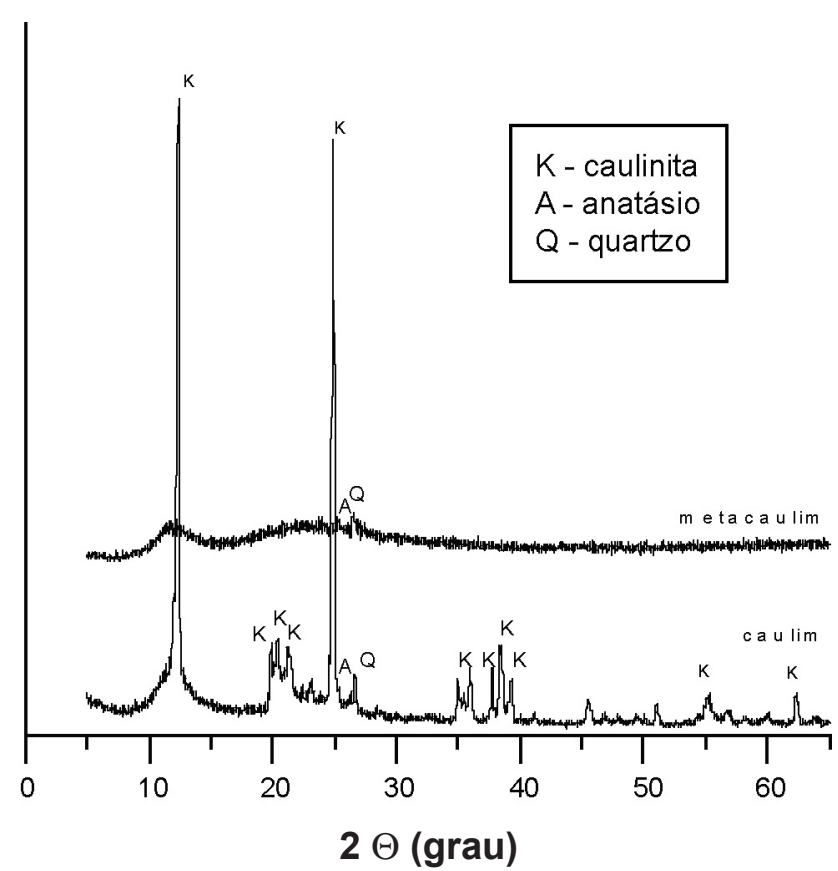

Figura 1: Difratograma de raios $\mathrm{X}$ do rejeito de caulim e após calcinação a $700{ }^{\circ} \mathrm{C} / 2 \mathrm{~h}$.

[Figure 1: XRD patterns of the kaolin waste samples and kaolin wastes calcined at $700{ }^{\circ} \mathrm{C} / 2 \mathrm{~h}$.] constituiu-se principalmente de muitas partículas aglomeradas, de morfologia pseudo-hexagonal, com destaque para formas do tipo "booklets", características do empilhamento dos cristais de caulinita. A metacaulinita que resultou da calcinação da caulinita a $700{ }^{\circ} \mathrm{C}$ em $2 \mathrm{~h}$ apresentou grande aglomeração de partículas, com a morfologia pseudo-hexagonal mantida, Fig. $2 \mathrm{~b}$.

As análises de DRX dos produtos de síntese M-80-24,
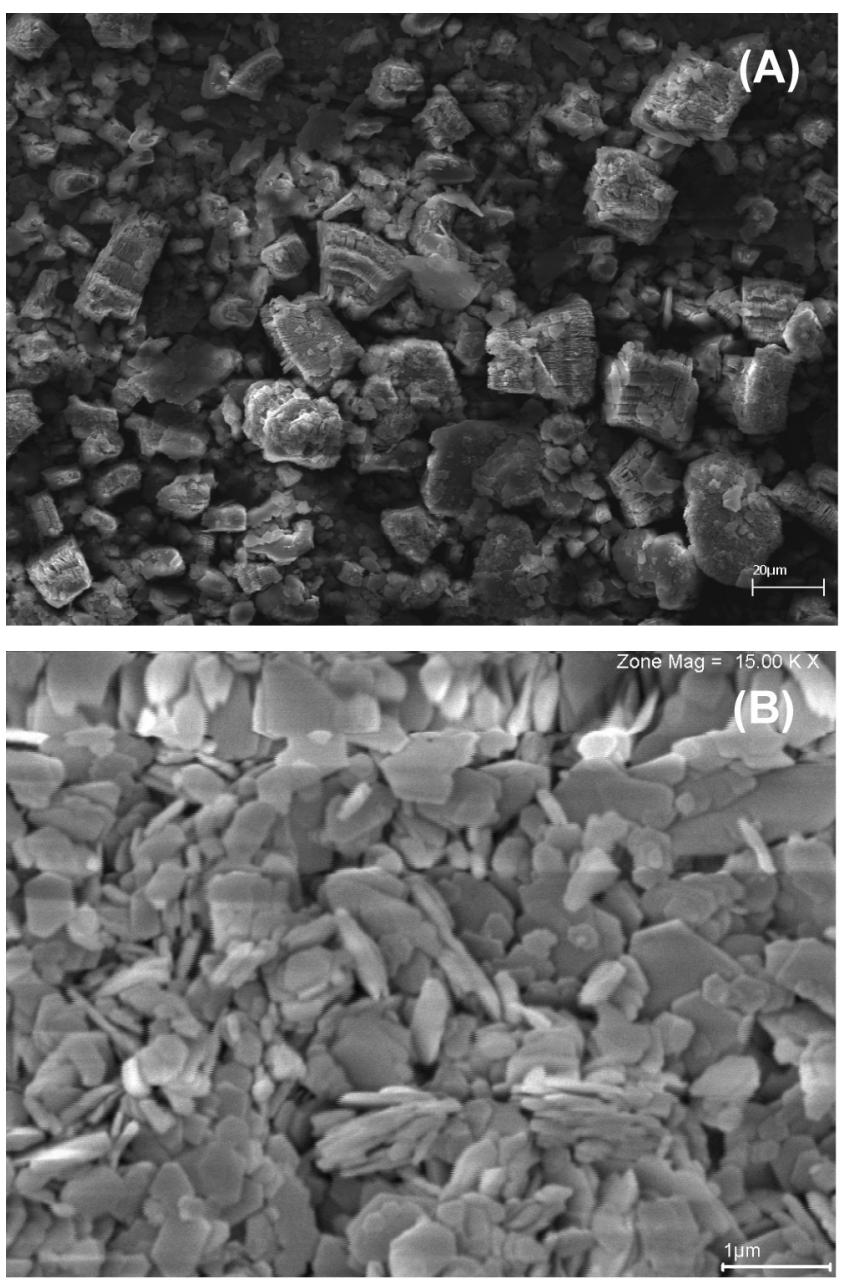

Figura 2: Imagens de microscopia eletrônica de varredura do rejeito de caulim (a) e da metacaulinita (b).

[Figure 2: SEM images of the kaolin waste sample (a) and metakaolinite (b).]

M-110-24 e M-150-24 são apresentadas nas Figs. 3, 4 e 5, respectivamente. O difratograma do produto M-80-24, Fig. 3, revelou ser semelhante ao da metacaulinita, utilizado como material precursor, caracterizado por grande quantidade de material amorfo, além de quartzo e anatásio. Para o produto M110-24, verificou-se a formação da zeólita A com elevado grau de ordem estrutural, com padrão difratométrico representado por picos estreitos e bem delineados, Fig. 4. No difratograma do produto M-150-24 foi constatada a formação de dois materiais cristalinos: zeólita A e hidroxisodalita. Essas duas fases apresentaram quantidades próximas, já que não foram identificadas divergências significativas nas intensidades 
relativas, Fig. 5. Para os produtos M-110-24 e M-150-24 foram verificados, através de seus respectivos difratogramas, picos característicos de quartzo e anatásio, mas em baixas intensidades. Esses dois minerais já estavam presentes no material de partida, portanto não são produtos de síntese. Também foram observadas para esses produtos quantidades significativas de material não cristalino provavelmente indicando que não houve total reação da metacaulinita. Dessa maneira, quanto a menor temperatura utilizada na síntese $(80$ ${ }^{\circ} \mathrm{C}$ ), foi constatado que não houve cristalização da zeólita $\mathrm{A}$. Para as temperaturas 110 e $150^{\circ} \mathrm{C}$ foi constatada a cristalização da zeólita $\mathrm{A}$, porém somente na menor temperatura de reação, essa zeólita foi sintetizada como único material cristalino. Quanto se aumentou a temperatura para $150{ }^{\circ} \mathrm{C}$, além da zeólita A foi também obtida a hidroxisodalita.

As imagens ao microscópio eletrônico de varredura dos

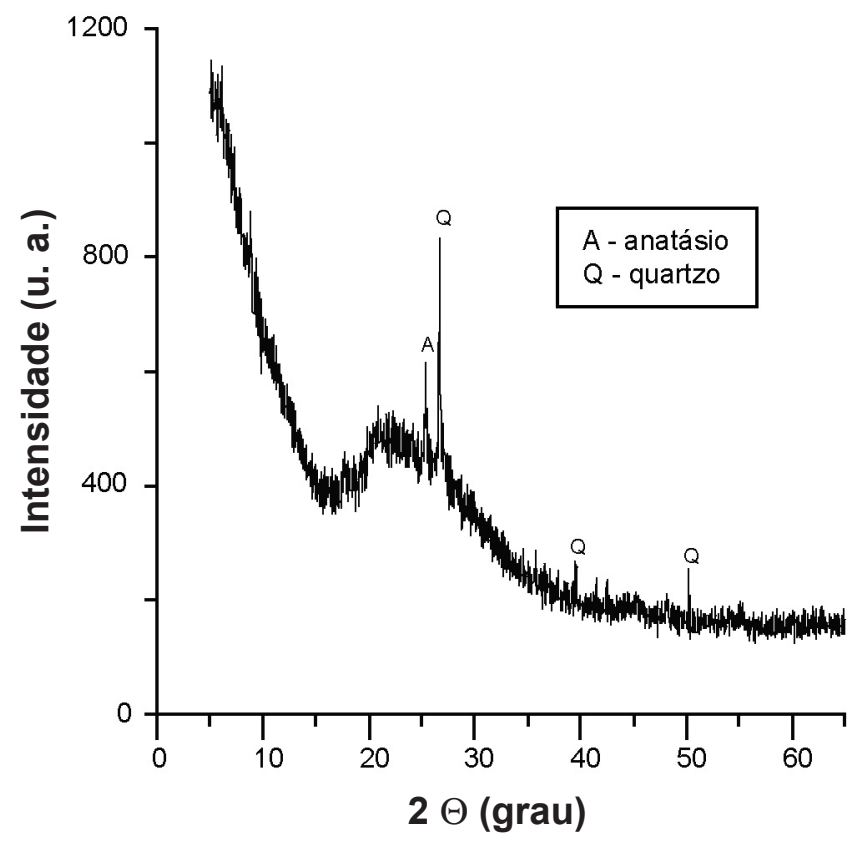

Figura 3: Difratograma de raios X do produto M-80-24.

[Figure 3: XRD patterns of the sample M-80-24.]

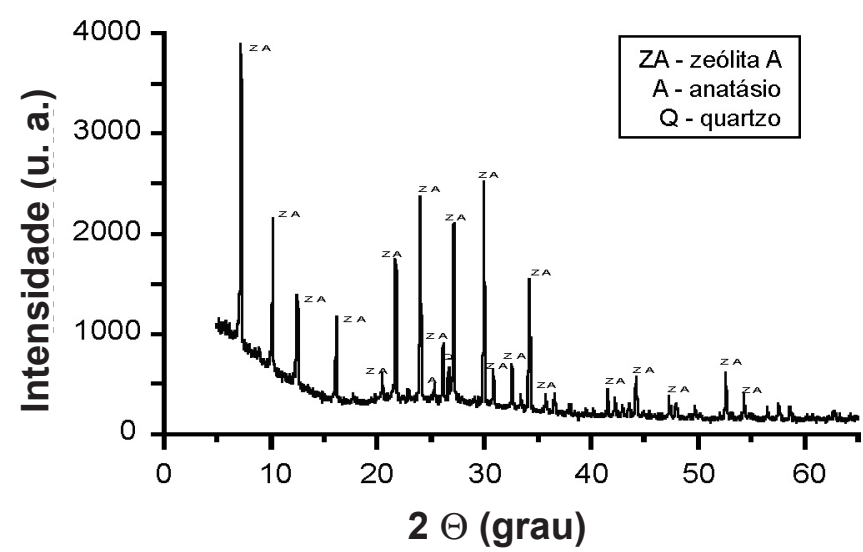

Figura 4: Difratograma de raios X do produto M-110-24.

[Figure 4: XRD patterns of the sample M-110-24.]

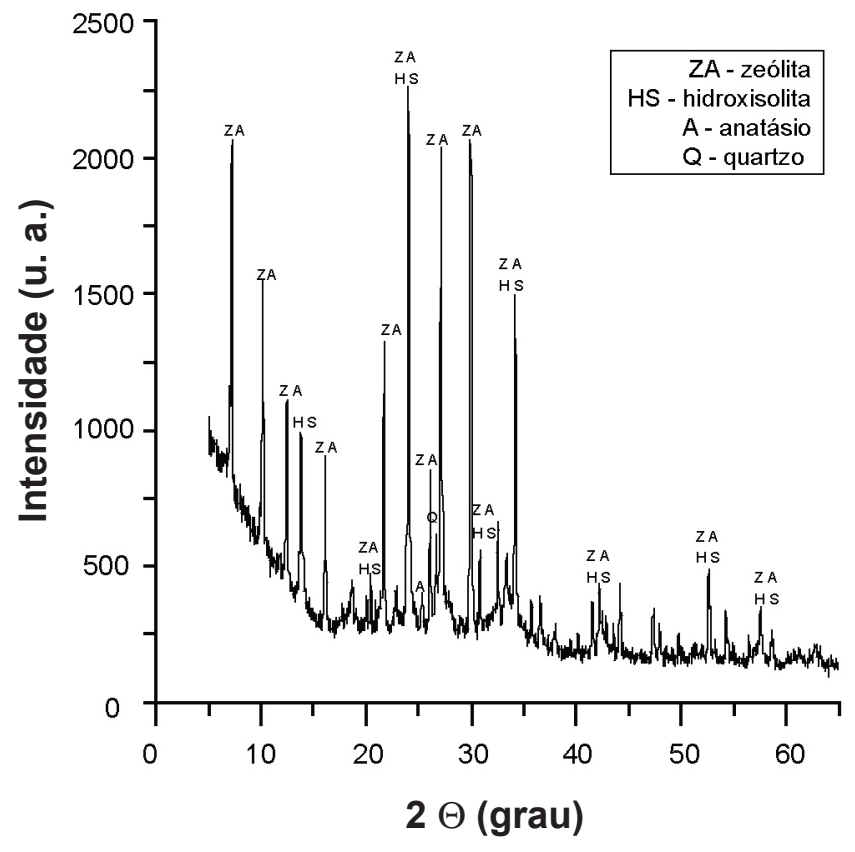

Figura 5: Difratograma de raios X do produto M-150-24.

[Figure 5: XRD patterns of the sample M-150-24.]

produtos de síntese M-110-24 e M-150-24 estão apresentadas na Fig. 6. Para o produto sintetizado a $110^{\circ} \mathrm{C}$ (M-110-24), foram observados na Fig.6a cristais cúbicos bem formados, que mostram uma morfologia típica da zeólita A. Esses cristais apresentam-se isolados, com presença de uma pequena quantidade de material amorfo, possivelmente metacaulinita que não reagiu. Quando se elevou a temperatura de síntese para $150^{\circ} \mathrm{C}$, o produto M-150-24 constituiu-se de cristais cúbicos, típicos da zeólita A e esferas de morfologia bem definida, característicos da hidroxisodalita, como pode ser verificado na Fig. 6 b.

Os espectros de infravermelho dos produtos M-110-24 e M-150-24 são apresentados nas Figs. 7 e 8, respectivamente. Foram verificadas bandas a 3477 e $1660 \mathrm{~cm}^{-1}$, para o M110-24, Fig. 7, e 3459 e $1660 \mathrm{~cm}^{-1}$, para o M-150-24, Fig. 8, atribuídas às águas zeolíticas. A presença de material zeolítico foi confirmada através das bandas em $1031 \mathrm{e} 990 \mathrm{~cm}^{-1}$, para os respectivos produtos M-110-24 e M-150-24. Essas bandas estão próximas à localizada a $1000 \mathrm{~cm}^{-1}$, que por sua vez é uma banda característica da ligação $\mathrm{Si}-\mathrm{O}-\mathrm{Al}$ do tetraedro $\mathrm{TO}_{4}$ [18]. Contudo, as bandas ao redor de 667, 549 e $443 \mathrm{~cm}^{-1}$ indicaram a cristalização da zeólita $\mathrm{A}$, para aquele produto sintetizado a $110{ }^{\circ} \mathrm{C}$, Fig. 7. O aumento da temperatura de síntese para $150^{\circ} \mathrm{C}$ contribuiu para a formação de um outro material zeolítico, a hidroxisodalita. Dessa forma, além das bandas características da zeólita A em 672, 549 e $425 \mathrm{~cm}^{-1}$, foram também encontrados no espectro do infravermelho, bandas referentes à hidroxisodalita em 672 e $608 \mathrm{~cm}^{-1}$, Fig. 8. A banda próxima a $557 \mathrm{~cm}^{-1}$ está conectada com a vibração do anel duplo de quatro tetraedros (D4R), que é dominante na unidade de construção secundária (SBU) da estrutura da zeólita A [19]. No produto M-150-24, ainda foi detectada uma banda localizada a $798 \mathrm{~cm}^{-1}$, indicando a presença de 

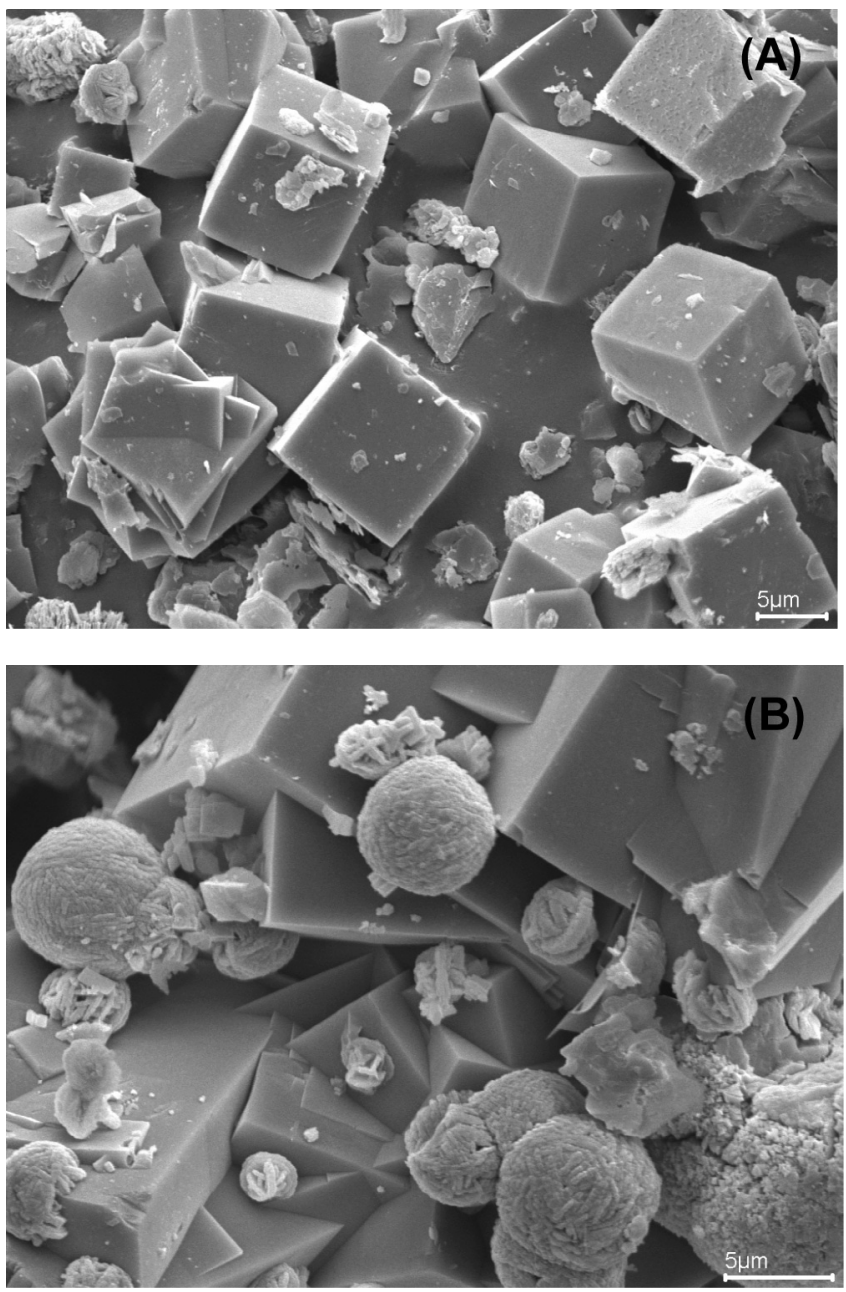

Figura 6: Imagens de microscopia eletrônica de varredura dos produtos M-110-24 (a) e M-150-24 (b).

[Figure 6: SEM images of the samples M-110-24 (a) and M-15024 (b).]

metacaulinita, material de partida, que possivelmente não reagiu totalmente.

Os gráficos de ATD/TG dos produtos M-110-24 e M-15024 sintetizados a partir de metacaulinita em $24 \mathrm{~h}$, variando-se a temperatura de 110 para $150^{\circ} \mathrm{C}$ são apresentados nas Figs. 9 e 10 , respectivamente. Foram verificados dois picos endotérmicos, através da análise termodiferencial, para os produtos M110-24, Fig. 9, e M-150-24, Fig. 10, um na temperatura de $175 \mathrm{C}$, relacionado à eliminação da água adsorvida, e outro em torno de $400{ }^{\circ} \mathrm{C}$, correspondente à desidratação do material zeolítico. Com o aumento da temperatura de síntese de $110{ }^{\circ} \mathrm{C}$ para $150{ }^{\circ} \mathrm{C}$ houve um aumento na intensidade do primeiro pico endotérmico, enquanto que no outro pico ocorreu um alargamento com essa mudança de temperatura. Nessas mesmas temperaturas, a análise termogravimétrica das amostras revelou uma perda de massa endotérmica devido à desidratação. Essa perda de massa teve início a $50{ }^{\circ} \mathrm{C}$ e foi quase completa a $400{ }^{\circ} \mathrm{C}$. Esses resultados estão de acordo com os encontrados para zeólita A [20].

$\mathrm{Na}$ análise térmica diferencial dos produtos M-110-24, Fig. 9, e M-150-24, Fig. 10, também são observados dois picos

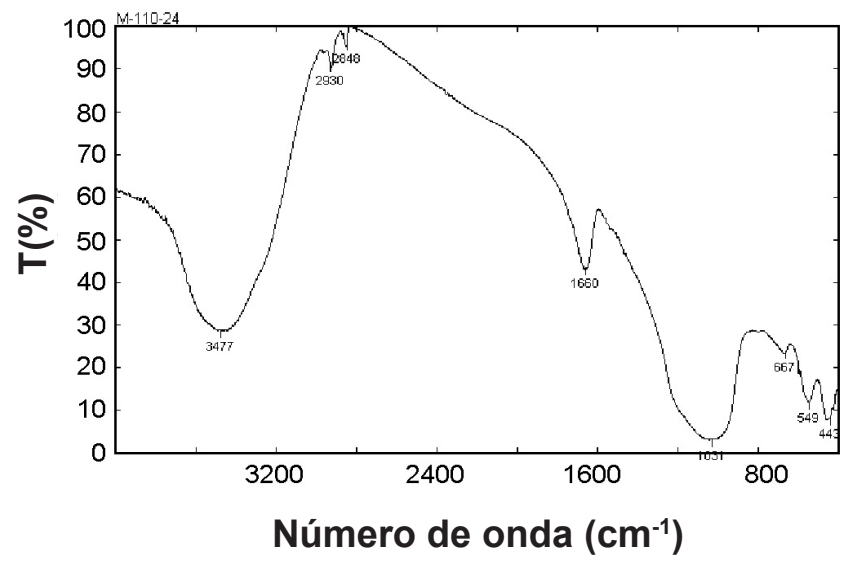

Figura 7: Espectro de infravermelho do produto M-110-24. [Figure 7: Infrared spectrum of the samples M-110-24.]

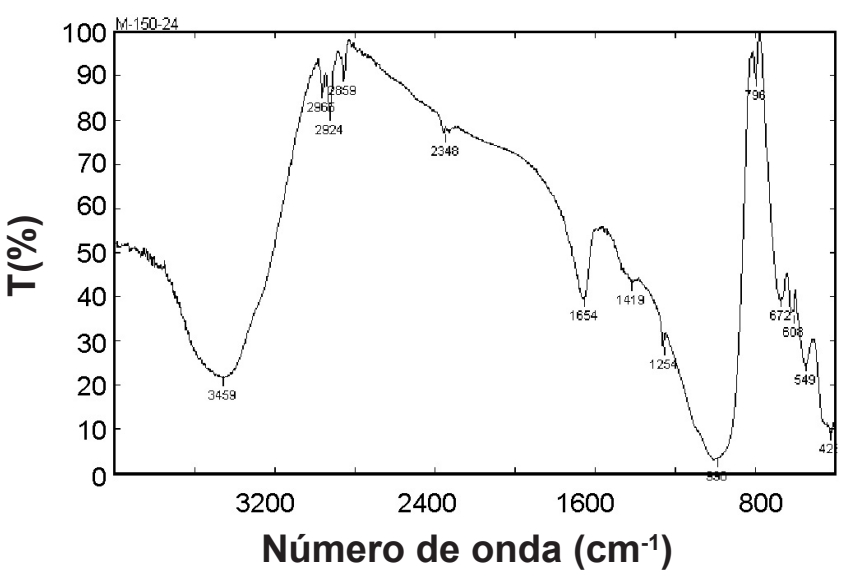

Figura 8: Espectro de infravermelho do produto M-150-24.

[Figure 8: Infrared spectra of the samples M-110-24.]

exotérmicos próximos a $900{ }^{\circ} \mathrm{C}$ e $950{ }^{\circ} \mathrm{C}$. Provavelmente, nessas temperaturas houve transformação da fase zeolítica em outras fases mineralógicas. Esses picos exotérmicos são comuns em zeólitas, sendo que o primeiro pico está associado com o colapso da estrutura cristalina para uma fase amorfa e o segundo pico é freqüentemente observado como um resultado da recristalização para uma nova fase [9].

$\mathrm{Na}$ análise termogravimétrica observou-se uma perda de massa total no aquecimento a $1000{ }^{\circ} \mathrm{C}$, em torno de $10,9 \%$ e $12,7 \%$ para os produtos M-110-24, Fig. 9, e M-150-24, Fig. 10, respectivamente, causada pelo aumento gradual da desidratação.

\section{CONCLUSÕES}

O rejeito de beneficiamento de caulim para papel, mostrouse como uma excelente matéria-prima para produção de zeólita A e hidroxisodalita, sendo dessa forma mais uma alternativa na tentativa de minimizar os impactos ambientais.

Embora outros autores tenham conseguido a síntese da zeólita A em temperaturas mais baixas, próximo de $70^{\circ} \mathrm{C}$ $[10,16,21]$, neste trabalho, a $80^{\circ} \mathrm{C}$ não houve formação de 


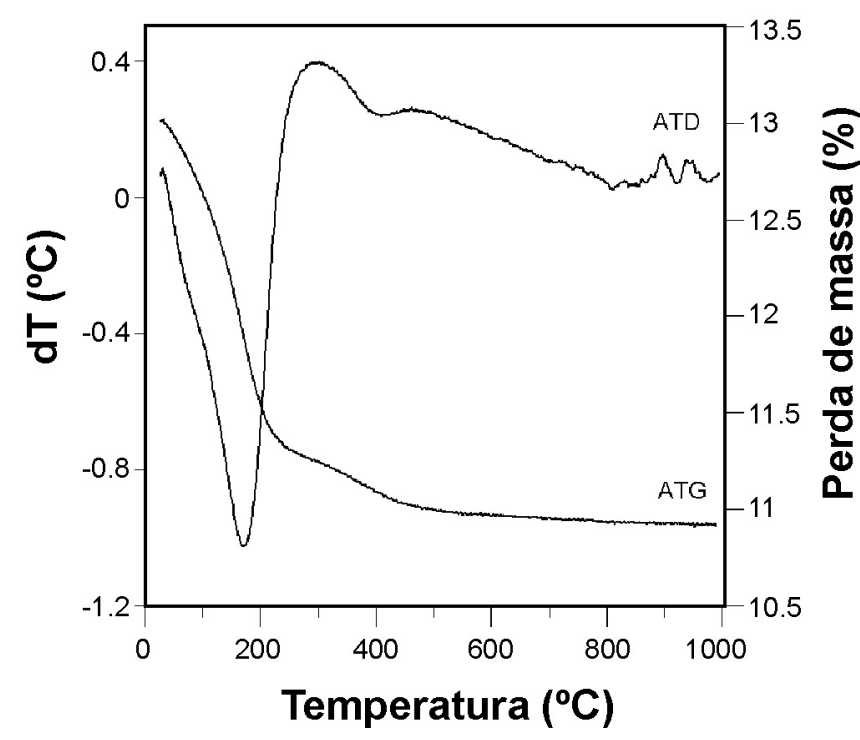

Figura 9: Análise térmica diferencial e termogravimétrica da amostra M-110-24.

[Figure 9: TG and DTA of the M-110-24 samples.]

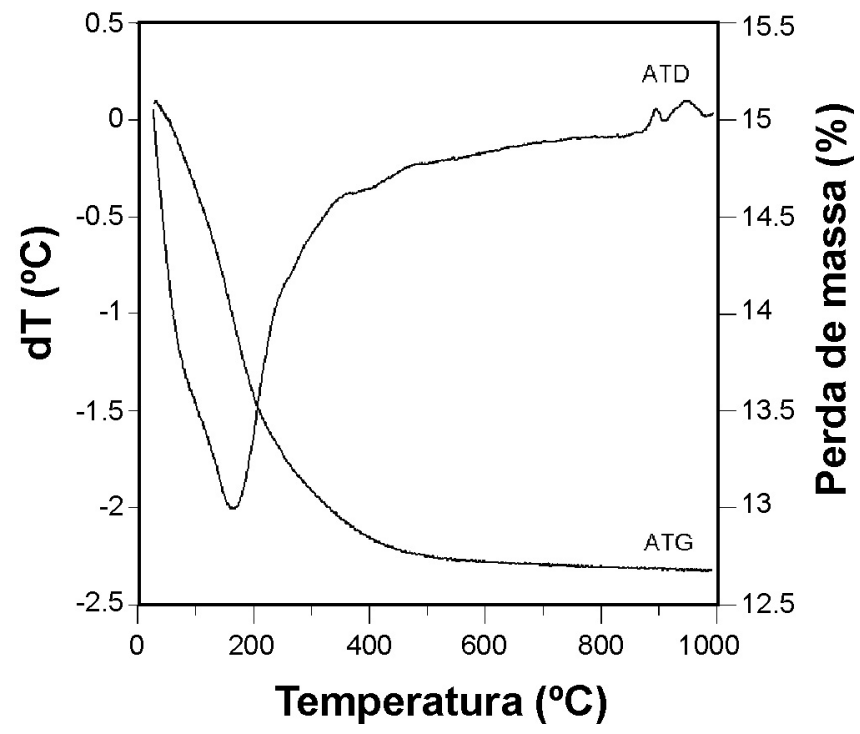

Figura 10: Análise térmica diferencial e termogravimétrica da amostra M-150-24.

[Figure 10: TG and DTA of the M-150-24 samples.]

nenhum material cristalino. Somente em temperaturas mais elevadas $\left(110\right.$ e $\left.150{ }^{\circ} \mathrm{C}\right)$ houve a cristalização dessa zeólita. Acredita-se que esta diferença esteja relacionada ao grau de ordenamento estrutural do material utilizado. Os rejeitos utilizados provêm de um nível de caulim constituído de caulinita de alta cristalinidade, cuja temperatura de desidroxilação para produção de metacaulinita é mais elevada [3, 22]

Para as condições estudadas, a temperatura de síntese é uma variável do processo que influenciou direto na formação da zeólita $\mathrm{A}$, pois a mesma só é formada pura a $110^{\circ} \mathrm{C}$. O aumento para $150{ }^{\circ} \mathrm{C}$ produziu uma mistura de zeólita A e hidroxisodalita.
Zeólita A e hidroxisodalita são formadas, não havendo formação de nenhuma outra fase cristalina, por difração de raios $\mathrm{X}$.

\section{REFERÊNCIAS}

[1] Departamento Nacional de Produção Mineral, Sumário Mineral (2006). http://www.dnpm.gov.br/.

[2] E. Saldanha, Síntese e caracterização da analcima a partir de rejeito de caulim e aplicação como adsorvente, Diss. Mestrado, Universidade Federal do Pará, Belém (2006).

[3] M. C. Martelli, Transformações térmicas e propriedades cerâmicas de resíduos de caulins das regiões do Rio Capim e do Rio Jarí- Brasil, Tese de Doutorado, Universidade Federal do Pará, Belém (2006).

[4] M. S. Barata, D. C. C. Dal Molin, Ambiente Construído 2, 1 (2002) 69.

[5] S. M. P. Flores, Aproveitamento do rejeito de caulim na produção de alumina para cerâmica e sílica de baixa granulometria, Tese Doutorado, Universidade Federal do Pará, Belém (2000).

[6] A. B. Luz, Série Tecnologia Mineral 68, Rio de Janeiro (1994).

[7] H. Yamada, S. Yokoyama, Y. Watanabe, H. Uno, K. Tamura, Science and Technology of Advanced Materials 6 (2005) 394.

[8] R. Grizzetti, G. Artioli, Microporous and Mesoporous Mater. 54 (2002) 105.

[9] J. A Rabo, Zeolite Chemistry and Catalysis, American Chemical Society, Washington, EUA (1974).

[10] A. Gualtiere, P. Norby, G. Artioli, J. Hanson, Physical Chemical Minerals 24 (1996) 191.

[11] L. H. Kallai, I. Lapides, Appl. Clay Science 35 (2007) 99.

[12] M. Alkan, C. Hopa, Z. Yilmaz, H. Güler, Microporous Mesoporous Mater. 86 (2005) 176.

[13] Y. Marui, M. Mtsuoka, J. Engineering Japan 37 (2004) 685. [14] S. Chandrasekhar, P. Raghavan, G. Sebastian, A. D. Damodaran, Appl. Clay Science 12 (1997) 221.

[15] K. Othmer, Encyclopedia de Chemical Technology, $3^{\text {rd }}$ Ed. (1978).

[16] D. W. Breck, Zeolitic Molecular Sieves: structure, chemistry and use, Wiley, N. York, EUA (1973).

[17] A. A. B. Maia, Síntese da zeólita A utilizando como precursor um rejeito de beneficiamento de caulim da Amazônia: aplicação como adsorvente, Diss. Mestrado, Universidade Federal do Pará, Belém (2007).

[18] A. Demortier, N. Gobeltz, J. P. Lelieur, C. Duhayon, Int. J. Inorg. Mater. 1 (1999) 129.

[19] S. Markovic, V. Dondur, R. Dimitrijevic, J. Molecular Struct. 654 (2003) 223.

[20] M. Afzal, G. Yasmeen, M. Saleem, P. K. Butt, A. K. Khattak, J. Afzal, J. Thermal Anal. Calorim. 62 (2000) 721.

[21] R. M. Barrer, Zeolites and Clay Minerals as Sorbents and Molecular Sieves. Academic Press, London (1978).

[22] B. S. Carneiro, R. S. Angélica, T. Scheller, E. A. S. de Castro, R. F. Neves, Cerâmica 49, 312 (2003) 237.

(Rec. 03/03/2007, Rev. 30/04/2007, Ac. 13/07/2007) 